\title{
PENERAPAN TRI HITA KARANA DALAM HARMONISASI KONSERVASI DAN BUDAYA DI DAYA TARIK WISATA KEBUN RAYA BALI
}

\author{
I Gst Ngurah Putu Dedy Wirawan ${ }^{1}$ dan I Made Raharja Pendit ${ }^{2}$ \\ 1,2 Balai Konservasi Tumbuhan Kebun Raya "Eka Karya" Bali LIPI \\ Email: dedywirawan76@yahoo.co.id
}

\begin{abstract}
This article examines the application of Tri Hita Karana (THK) values involving the harmonisation of conservation and culture at the Bali Botanic Garden, Tabanan, Bali. THK is an Hindu beliefs with three main harmonious concepts including harmony among people, harmony with the natural environment and harmony with God. Balinese recognise ecosystem-based nature management, as in the term Tri Mandala, three different level of spaces according to the purpose and benefits of parhyangan (holy place), palemahan (environment) and pawongan (human). These three spaces according to Balinese culture must be harmonious, balanced and preserved in order to support conservation efforts. Combined conservation efforts with cultural values is also a theme that has been utilized by the Bali Botanic Garden in building thematic collections, such as the collection of medicinal plants, traditional ceremonial plants, and ethnobotany artefacts. This collections insight into Balinese cultural conservation supports educational and tourism services at Bali Botanic Garden. The implementation of THK philosophy at Bali Botanic Garden has an important to improves resource efficiency, maintains relationships with the creators, conserves the environment and culture, and maintains harmony in reducing conflict, social imbalances and ensures the sustainability of regional development.
\end{abstract}

Keywords: Tri Hita Karana, culture, harmony, Bali Botanic Garden, plant conservation

\section{Abstrak}

Artikel ini mengkaji penerapan nilai-nilai Tri Hita Karana (THK) dalam harmonisasi konservasi dan budaya di Kebun Raya 'Eka Karya', Tabanan, Bali. THK merupakan filosofi Hindu yang memiliki tiga pilar untuk menciptakan keharmonisan antara umat manusia, manusia dengan alam lingkungan, serta 
dengan Tuhan. Selain itu, masyarakat Bali juga mengenal pengelolaan alam yang berbasis ekosistem, seperti dalam istilah Tri Mandala, tiga tingkatan ruang sesuai manfaat yaitu Prahyangan (tempat suci), Palemahan (lingkungan), dan Pawongan (manusia). Ketiga ruang sesuai dengan budaya Bali tersebut harus selaras, seimbang, dan terpelihara sehingga dapat merupakan salah satu tindakan konservasi. Konservasi yang terpadu dengan nilai-nilai budaya tersebut juga telah diciptakan oleh Kebun Raya Bali dengan membangun koleksi tematik, seperti koleksi tumbuhan usada, koleksi tumbuhan upacara adat, dan koleksi artefak etnobotani. Rangkaian kegiatan yang berwawasan konservasi budaya masyarakat Bali ini mendukung pelayanan pendidikan dan wisata di Kebun Raya. Penerapan konsepsi THK di Kebun Raya Bali memiliki peranan untuk meningkatkan efisiensi sumber daya, menjaga hubungan dengan sang pencipta, konservasi lingkungan dan budaya, serta menjaga keharmonisan dalam mengurangi konflik, mengurangi ketimpangan sosial, dan menjamin keberlanjutan pembangunan wilayah.

Kata kunci: Tri Hita Karana, Budaya, Keharmonisan, Kebun Raya Bali, Konservasi tumbuhan.

\section{Pendahuluan}

Masyarakat Bali mengenal Tri Hita Karana (THK) yang merupakan filosofi mengenai tiga hubungan harmonis untuk mencapai kebahagiaan yaitu hubungan manusia dengan Tuhan (parhyangan), manusia dengan sesama (pawongan), dan manusia dengan alam (palemahan). Filosofi THK ini sudah diakui dan menjadi landasan berbagai ketentuan, buktinya dimuat dalam aturan adat (awig-awig), dan perencanaan tata ruang wilayah Provinsi Bali (Perda No. 16 Tahun 2009). Artikel ini mengkaji penerapan nilai-nilai Tri Hita Karana (THK) dalam harmonisasi konservasi dan budaya di Kebun Raya ‘Eka Karya', Tabanan, Bali.

Konsep THK telah dikemas oleh Kebun Raya Bali dalam salah satu kegiatan penelitian etnobotani dengan membangun Taman Upacara Adat Hindu Bali (TUAHB) pada areal Taman Panca Yadnya, dan Tanaman obat tradisionil Bali dalam bentuk Taman Usada. Selain itu terkait dengan budaya masyarakat Bali dalam memanfaatkan tumbuhan juga dibangun Meseum Etnobotani Kebun Raya Bali. Taman Usada (pohon potensi untuk obat-obatan) dan Taman Panca Panca Yadnya (lima jenis uoacara korban suci) yang telah dibangun tersebut merupakan koleksi tematik yang dimilki oleh Kebun Raya Bali sebagai lembaga konservasi eks-situ tumbuhan. Tidak 
kurang dari 1200 jenis tanaman koleksi yang telah dimiliki, diantaranya 320 koleksi usada dan 215 koleksi tanaman panca yadnya (tanaman upacara adat).

Keragaman atau jumlah jenis tanaman upacara adat yang digunakan oleh masyarakat di Bali bervariasi, dan berbeda sesuai dengan adat masingmasing daerah. Berdasarkan hasil penelitian jumlah tanaman yang dipakai sebagai bahan upacara terbanyak oleh masyarakat di Kabupaten Bangli yaitu sebanyak 241 jenis. Jenis tanaman relative lebih banyak digunakan pada upacara Dewa yadnya dan Pitra yadnya (Tirta, 2004). Selain tumbuhan dimanfaatkan untuk kehidupan pada hari tertentu yang disebut Tumpek Wariga dilakukan persembahyangan atau mempersembahkan sesajen untuk semua tumbuhan, dilakukan secara symbolis pada beberapa tanaman yang ada di kebun, sawah, tegalan, dan tempat lainnya. Upacara ini bermakna untuk bersyukur kepada Tuhan Yang Maha Esa, menghargai dan menjaga keberadaan tumbuhan dan alam dimana manusia hidup dan ketergantungan dari alam itu sendiri.

Banyak potensi alam yang telah diketahui dan dimanfaatkan untuk kepentingan kehidupan secara tradisional dan tidak sedikit telah diproduksi dengan sentuhan teknologi modern. Dengan kemajuan ilmu pengetahuan dan teknologi ke depannya cenderung akan lebih banyak dapat terungkap potensi alam yang sementara belum diketahui.

Dalam hal ini terkait dengan tugas pokok dan fungsi Kebun Raya Bali sebagai lembaga konservasi tumbuhan dengan penelitiannya di bidang botani menggali potensi alam yang ada. Selanjutnya produk hasil penelitian dalam bentuk kebun botani sangat penting sebagai sumber ilmu pengetahuan botani bagi masyarakat, termasuk pengetahuan tentang budaya Bali dalam mewujudkan keharmonisan sesuai dengan konsep THK.

Konservasi tumbuhan yang dipakai dalam budaya Bali dikemas oleh Kebun Raya Bali dalam bentuk koleksi tematik yang ditata dalam bentuk taman, sehingga menjadi salah pendukung dalam penyediaan jasa wisata. Konsep THK sangat relevan jika diterapkan pada objek wisata, karena THK tidak hanya memperhatikan hubungan harmonis dengan lingkungan saja, tetapi hubungan dengan manusia dan juga hubungan dengan Tuhan.

Jika dikaji secara mendalam pengembangan obyek wisata cenderung akan berkembang lebih baik dan menarik bagi masyarakat, seperti salah satu kegiatan pengembangan wisata flora di Kebun Raya Bali. Hal ini didukung dengan keberadaan Kebun Raya Bali sebagai salah satu pusat pendidikan botani dengan berbagai produk-produk penelitiannya dalam bidang konservasi tumbuhan.

Lebih dari 2100 jenis tumbuhan yang terdapat di Kebun Raya Bali merupakan kekayaan yang sangat besar untuk penelitian, pendidikan, dan gudang keunikan genetika tumbuhan, diantaranya dikemas dalam koleksi 
thematic tersebut Selain itu keberadaan tanaman koleksi ini juga berpotensi untuk tujuan restorasi dalam pengembangan wisata untuk masyarakat luas. Tidak sedikit masyarakat memanfaatkan kunjungan wisata dan pendidikan di Taman Usada dan Taman Panca Yadnya, sebagai koleksi thematiknya Kebun Raya Bali.

Kebun Raya "Eka Karya” Bali merupakan salah satu kawasan wisata alam yang memiliki potensi sebagai konservasi, pendidikan, serta tujuan wisata, yang tidak dimiliki oleh obyek wisata lainnya, Kebun Raya Bali, berdiri sejak tahun 1959. Namun demikian berdasarkan hasil wawancara dengan Kepala Kebun Raya Bali diketahui bahwa tingkat kunjungan wisatwan mengalami fluktuasi, serta pemahaman masyarakat tentang obyek wisata masih kurang. dapat dilihat pada tabel berikut:

Table 1 Kunjungan Wisatawan Ke kebun Raya Bali Tahun 2012-2016

\begin{tabular}{cccc}
\hline Tahun & Wisatawan Lokal & Wisatawan Asing & TOTAL \\
\hline 2012 & 29.511 & 21.269 & 50.780 \\
2013 & 20.725 & 24.855 & 45.580 \\
2014 & 16.531 & 23.159 & 39.690 \\
2015 & 20.745 & 25.584 & 46.329 \\
2016 & 514.246 & 54.541 & 568.787 \\
\hline
\end{tabular}

Sumber: Unit jasa dan informasi Kebun Raya Bali

Umumnya objek ini lebih banyak dikunjungi dari khalangan pelajar dan mahasiswa dan kunjungan dari masyarakat umum. Di Kebun Raya Bali pengunjung dapat melihat beragam jenis tumbuhan dan kegunaannya dari masing-masing jenis secara tradisionil sesuai dengan budaya masyarakat Bali. Beberapa informasi tentang pemanfaatan bagian dari jenis tumbuhan dan cara pembuatan ramuan obat tertentu bisa dilihat di Taman Usada, namun jika masyarakat berminat mengetahui informasi lebih lengkap bisa diperoleh via pemanduan.

Kebun Raya Bali juga mengoleksi artefak etnobotani yang dipajang pada ruang pamer rumah tradisional Bali. Sehubungan dengan koleksi artefak etnobotani yang memiliki potensi sebagai daya tarik wisata, Setiadi \& Lusilaora (2017) menegaskan perlunya pemeliharaan dan pengembangan secara berkelanjutan, meliputi dukungan fasilitas dan promosi.

In line with its function as a plant conservation body which is also a tourist destination area, the potential of the collections related to ethnobotany needs to be further developed. Certainly, commitment of the management to develop the ethnobotanical tourism in the area is required. Provision of supporting facilities, cooperation with relevant parties such as tourism businesses, local governments, and the public is absolutely needed. Promotional activities 
must be intensified in order that the ethnobotanical tourism potential can be developed well and has positive benefits for science, the tourism industry and the welfare of the communities (Setiadi \& Lusilaora 2017)

Dari kutipan di atas pihak pengelola dalam mengembangkan wisata etnobotani sangat dibutuhkan karena sejalan dengan fungsinya sebagai sebuah lembaga konservasi tumbuhan yang juga menjadi kawasan tujuan wisata, dalam menjaga keharmonisan budaya dan alam

Demikian juga informasi yang ada pada koleksi tanaman upacara adat di Taman Panca Yadnya yang ditata berdasarkan jenis upacara adat di Bali yang disebut dengan Panca Yadnya. Secara arfiah Panca Yadnya berarti lima pengorbanan suci (upacara) yang dilaksanakan oleh umat Hindu di Bali antara lain Dewa Yadnya (upacara persembahan untuk para Dewa), Resi Yadnya (upacara untuk para Resi/rohaniawan), Manusa Yadnya (upacara untuk keselamatan manusia), Pitra Yadnya (upacara untuk menghormati para leluhur), dan Bhuta Yadnmya (upacara untuk persembahan para bhuta kala). Lima jenis upacara yang dilaksanakan oleh masyarakat di Bali tersebut merupakan salah satu penerapan konsep THK dalam keseimbangan kehidupan yang harmonis.

\section{Metodelogi dan Pembahasan}

Penelitian ini merupakan penelitian deskriptif kualitatif, terkait penerapan THK dalam keharmonisan konservasi dan budaya di Kebun Raya Bali. Analisis deskriptif kualitatif disajikan dalam bentuk tabulasi maupun gambar mengenai penerapan THK dalam keharmonisan konservasi dan budaya, dibandingkan dengan literatur yang mendukung.

Lokasi penelitian adalah di Balai Konservasi Kebun Raya "Eka Karya" Bali-LIPI, Ds Candikuning, Kec. Baturiti, Kab Tabanan. Jenis pengambilan data dengan cara: wawancara, Observasi lapangan, Studi Literatur, dan Teknik Penentuan informan terkait dengan informasi terhadap nilai THK di lingkungan Kebun Ray Bali.

Tabel 2 Informan diarea Kebun Raya Bali

\begin{tabular}{lc}
\hline \multicolumn{1}{c}{ Informan } & Metode Pengambilan data \\
\hline Kepala Kebun Raya Bali & Wawancara Mendalam \\
Tokoh (purnabakti pegawai Kebun Raya Bali) & Wawancara Mendalam \\
Mangku (Orang suci) Pura Teratai Bang & Wawancara Mendalam \\
Mangku (Orang suci) Pura Giri Putri & Wawancara Mendalam \\
Pengurus Pura di Kebun Raya Bali & Wawancara Mendalam \\
\hline
\end{tabular}

Tri Hita Karana (THK) merupakan penerapan isi dari ajaran Kitab Suci Weda yang telah ada sejak tahun 1969 (Peters dan Wisnu 2013). Utama 
dan Nanniek (2011) mengemukakan filosofi THK ini menggambarkan tiga hubungan harmonis antara manusia dengan Tuhan (parahyangan), manusia dengan manusia (pawongan) dan manusia dengan alam (palemahan). Parahyangan merupakan kewajiban setiap manusia untuk mendekatkan dirinya kepada Sang Pencipta (aspek budaya), pawongan merupakan sebuah pengakuan yang tulus dari manusia itu sendiri, bahwa manusia tidak dapat hidup menyendiri (aspek sosial), sedangkan palemahan adalah bentuk kesadaran manusia bahwa manusia hidup dan berkembang di alam, dan merupakan bagian dari alam itu sendiri (aspek ekologi).

Secara umum kehidupan ini sangat ketergantungan dengan kondisi alam sekitar kita yang patut dijaga kelestariannya. Terkait dengan kelestarian sumberdaya alam tersebut, Kitab Bhagavad Gita IV.31 menyebutkan "nayam loka 'sty ayajnasya" yang berarti bahwa sumber daya alam digunakan untuk memenuhi kebutuhan hidup manusia dan dilestarikan atas dasar ketulus ikhlasan (yadnya). Yadnya merupakan dasar dalam pelaksanaan kegiatan bagi masyarakat Hindu Bali yang diimplementasikan kedalam filosofi (tattwa), etika (susila) dan ritual (upacara). Terdapat sarana kegiatan upacara yang digunakan dalam yadnya yaitu buah, bunga, daun dan air seperti yang tersurat dalam Bhagawad Gita IX.26 "patram puspam phalam toyam yo me bhaktya prayacchati tat aham bhakty-upahrtam asnami prayatatmanah" (siapapun yang dengan sujud bhakti kepada-Ku mempersembahkan sehelai daun, sekuntum bunga, sebiji buah-buahan, seteguk air, Aku terima sebagai bhakti persembahan dari orang yang berhati suci). Keempat sarana tersebut harus ada disetiap upacara keagamaan. Jika dicermati, hal ini mengandung makna pemanfaatan yang berkelanjutan terhadap sumberdaya alam hayati dan non hayati.

Ketiga aspek dalam THK merupakan prinsip utama dalam keberhasilan dalam berbagai aspek kehidupan, diantaranya termasuk dalam dunia pariwisata yang kini semakin berkembang pesat, terutama pada kawasankawasan wisata di Bali. Pengembangan dan pengelolaan bidang pariwisata tersebut juga memiliki unsur-unsur ekologi, sosial budaya dan relegi seperti yang terdapat di area wisata Kebun Raya Bali. Keberadaan Kebun Raya Bali pada kawasan wisata pegunungan di Bedugul yang disekitarnya terdapat vegetasi hutan hujan tropis.

Sebagai tempat wisata Kebun Raya Bali berada dalam kawasan tridanau. Tiga danau yang terdapat pada kawasan antara lain Danau Berata, Danau Buyan, dan Danau Tamblingan. Dari sisi ekologi kawasan Bedugul sebagai sumber mata air untuk daerah Bali selatan dan Bali bagian Utara. Selain keberadan ekologi pada kawasan tersebut terdapat beberapa pura besar (Pura Khayangan) sebagai tempat persembahyangan seluruh Umat Hindu, diantaranya telah dibangun sejak zaman neolitik (abad 14) seperti Pura Batu Meringgit. 


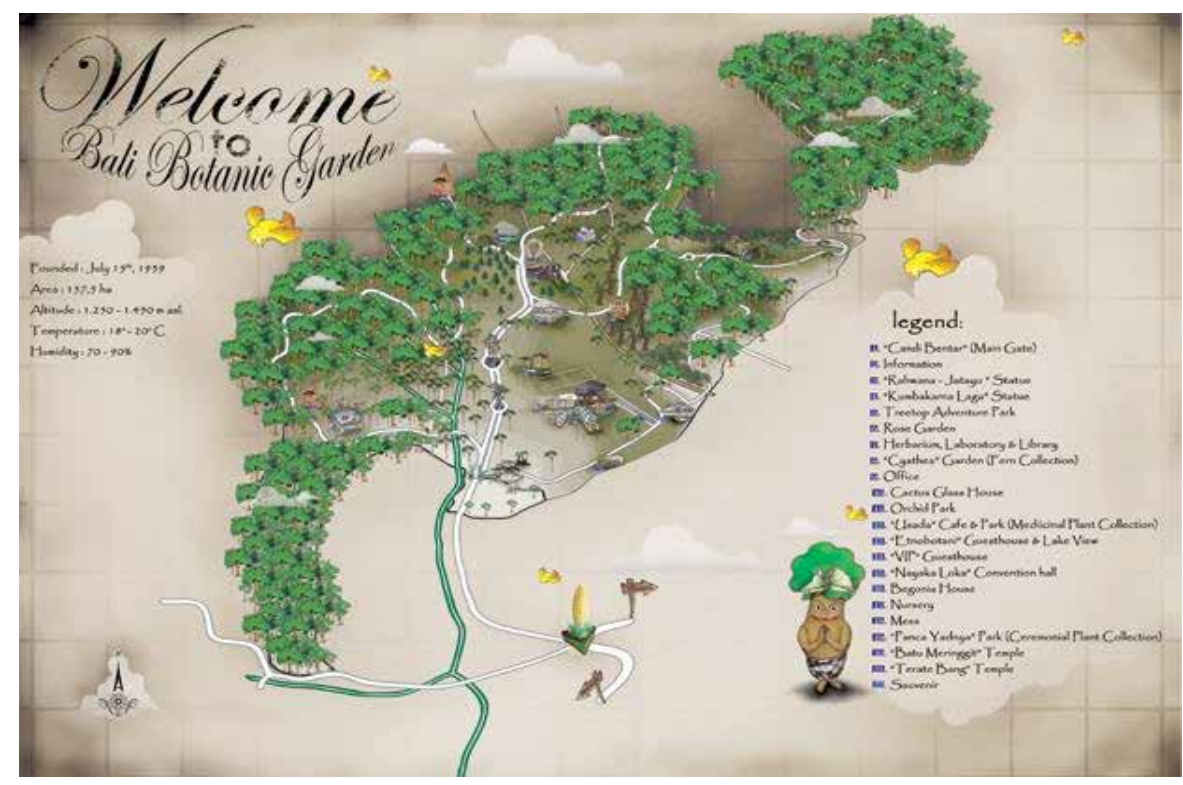

Foto 1. Peta area Kebun raya Bali (Dokinfo Kebun Raya Bali)

\section{Penerapan Tri Hita Karana dalam Harmonisasi Budaya Konservasi}

Secara umum kawasan yang ada di areal Kebun Raya Bali dan sekitarnya memiliki medan dengan kondisi terjal, struktur tanah letusan gunung api sehingga rawan longsoran dengan type longsoran Mud Flow (Suyarto, 2002).

Upaya konservasi telah dilakukan oleh berbagai pihak termasuk Kebun Raya Bali dalam kegitan reintroduksi jenis-jenis tumbuhan yang bersal dari kawasan setempat. Kegitan ini dilaksanaakan dengan kerja sama dari berbagai pihak terkait dan khalangan masyarakat. Jika dicermati konsep konservasi lingkungan telah ada dalam budaya masyarakat Bali terkait dengan keyakinan dan pilosofi masyarakat di Bali untuk mewujudkan kehidupan yang berkeseimbangan dan nyaman seperti yang dikenal dengan Tri Mandala. Konsep dari pilosofi Tri Mandala ini adalah mewujudkan tiga ruang yang jelas, selaras dan siembang yaitu Utama mandala, Madia Mandala, dan Nista Mandala. Ketiga ruang ini jelas dan tidak boleh tumpang tindih, karena masing-masing memiliki makna tersendiri namun secara keseluruhan menjadi satu kesatuan dalam mewujudkan keseimbangan kehidupan dalam alam lingkungan sebagai tempat tinggal dan beraktivitas. Alam lingkungan di Kebun Raya Bali secara alami merupakan kawasan pegunungan dengan vegetasi hutan hujan tropis, vegetasi tumbuhan koleksi dan tanaman hias landsekape, serta adanya pura sebagai zona religius umat Hindu di Bali sebagai pelengkap bagi masyarakat dalam menikmati alam Kebun Raya Bali. Di didalam kawasan Kebun Raya Bali terdapat tiga bangunan pura yaitu Pura Batu Meringgit (tahun 1123), Teratai Bang (abad 


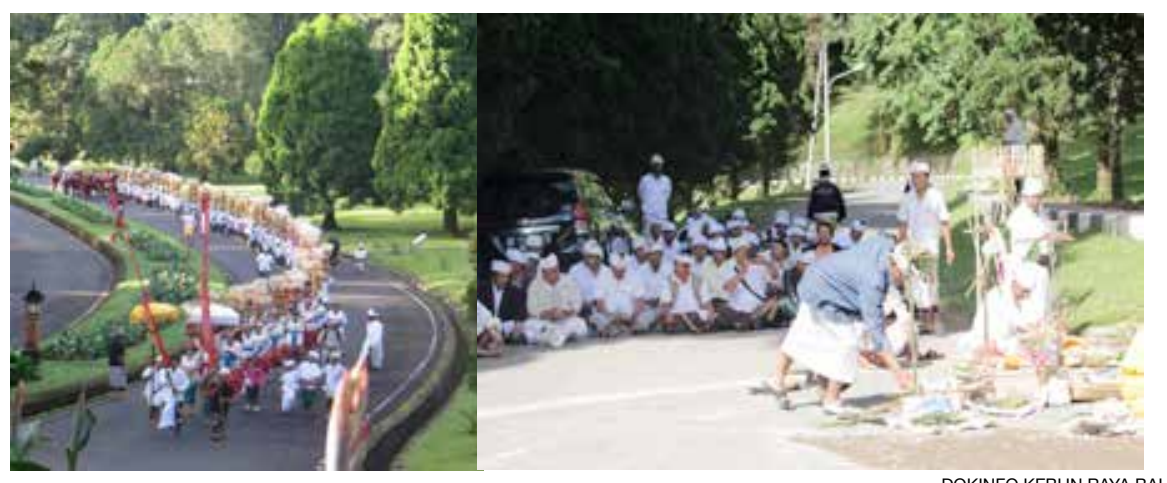

Foto 2. Kiri: Upacara yadnya yang dilakukan masyarakat setempat dan kanan: kegiatan mecaru oleh karyawan Kebun Raya Bali untuk keseimbangan alam.

16), dan pura Giri Putri (tahun 1963). Sejarah keberadaan tiga pura ini menjadi asset budaya masyarakat di Bedugul yang berdampingan dengan Kebun Raya Bali dan memperkaya informasi dalam kemasan wisata budaya.

\section{Hubungan Manusia dengan Pencipta}

Masyarakat sekita area kebun raya bali mempercayai pura-pura yang ada di Kebun Raya Bali merupakan salah satu pura peninggalan jaman kuno dulu sehingga masing-masing desa yang ada di kawasan Kebun Raya Bali, dipercaya sebagai pengempon pura dimana terdapat beberapa pura seperti: Pura Batu Meringgit, Pura Teratai Bang dan Pura Giri Putri.

Dari Foto2, aktifitas kegiatan masyarakat dalam melaksakan upacara keagaman, di kawasana pura Kebun Raya bali, menunjukan bahwa hubungan manusia dengan sang pencipta dengan melaksanakan upacara yadnya yang dilakukan setiap enam bulan sekali.

Dari hasil wawancara dengan mangku-mangku masing-masing pura, serta bendesa adat pengempon pura diperoleh data sebagai berikut.

\section{Pura Batu Meringgit}

Pura Batu Meringgit adalah pura kuno dan sederhana karena merupakan kumpulan setumpuk batu yang bagaikan ukiran alami (meringgit). Disebutkan dalam purana, pura tersebut terletak di Bukit Watu Meringgit dibangun ole Shri Jaya Kasunu pada abad 13 (tahun 1123 saka / 1201 Masehi) merupakan tempat memuja kebesaran Tuhan Yang Maha Esa dalam manifestasinya (Prabawanya) sebagai Sanghyang Iswara/Ciwa. Sejak tanggal 25 Januari 1999 pura tersebut telah ditetapkan sebagai Cagar Budaya No. 114021402001979 (Sudarsana, 2002). Pemugaran pura sempat dilaksanakan pada 1 Juli 2004 sekalian dilakukan perluasan areal pura menjadi 2 ha yang dibagi atas tri mandala yakni Utama, Madya dan 
Nista mandala (Sumantera, 2004). Pura tersebut pertama kali diketemukan oleh Jro Mangku Rugeg tahun 1938 dan kini dipuja (sungsung) oleh 116 Kk masyarakat Pemuteran. Pura yang terletak di kebun raya bagian selatan,

\section{Pura Teratai Bang}

Pura Teratai Bang diperkirakan didirikan abad 16 disebutkan sebagai anak dari Pura Batu Meringgit abad 13 sebagai "ibu" dan Pura Bukit Sangkur sebagai "bapak"nya. Letaknya di barat kebun raya, berada di tepi sumber belerang yang berbau kentut terutama saat sore hari berkabut. Belerang tersebut menghasilkan tirtha unik yang populer disebut Tirtha Masem karena rasanya pahit keasem-aseman dan dipercaya berkhasiat obat (tamba) terutama penyakit kulit. Disebelah timurnya terdapat mata air yang dahulunya merupakan sumber air minum masyarakat sekitarnya. Mata air yang disebut Beji merupakan sumber air kebutuhan tirtha, tempat menyucikan pratima dalam mekiis dan sebagai sumber air minum maupun kamar kecil. Pura tersebut diemong oleh $87 \mathrm{Kk}$ Krama Banjar Bukit Catu mulai dipugar tahun 1992. dan diperluas tahun 2002 menjadi 5 ha sehingga mampu lebih banyak warga pemedek sembahyang dalam kurun waktu 3 - 12 hari.

\section{Pura Giri Putri}

Pura Giri Putri dibangun oleh Kebun Raya Eka Karya Bali tahun 1993 beada di ketinggian kebun di bagian utaranya. Sesuai dengan namanya yang berarti putri gunung (giri=gunung) maka pura tersebut sebagai tempat pemujaan tuhan gunung/hutan/tumbuhan yang disebutkan sebagai ibu seperti diuraikan dalam Reg Veda X.97.A Osadhir iti mataras tad vo devir upa gruhe = tumbuhan memberi makan dan melindungi alam semesta . Pembangunan Pura Giri Putri sebagai upaya dalam melindungi sumber air demi keselamatan tumbuhan dan kesejahteran masyarakat yang ada di kebun raya Bali dan sekitarnya. Pada setiap Odalan umat Hindu pegawai kebun raya Bali melaksanakan upacara untuk memohon kesejahteraan dan mohon diberkahi kesinambungan keberadaan sumber air di lokasi setempat. Sumber air lainnya seperti Danau Beratan, ketersedian airnya ketergantungan dengan sestem hydrologi hutan Bukit Tapak yang ada disekitar Kebun Raya Bali dan Danau Beratan juga merupakan reservoir alam sebagai sumber air untuk kawasan Bali Selatan.

Keberadaan tiga pura di kawasan Kebun Raya Bali menunjukkan kawasan hutan tersebut adalah kawasan suci dan beraura magis (keramat), sehingga patut mendapat perlindungan secara nyata/ sekala dan secara gaib/niskala. Oleh karena itu para pengemong pura secara rutin melakukan upacara piodalan serta tidak mengganggu hutan keramat sekitarnya. Aksi nyata (kirti) demikian merupakan implementasi yang tersirat dan tersurat 
dalam Bhagawadgitha B.G. III, 14 ; Annaad bhavanti bhuutaani parjanyaad annasambhava yajnad bhavati parjanyo yajnah arma samubhavah yang artinya karena makanan, mahluk hidup, karena hujan, makanan tumbuh, karena persembahan hujan turun dan persembahan lahir karena kerja. Seloka tersebut mengungkapkan peran penting pura dalam konservasi air/ hujan dan tumbuhan. Berkat aktifitas kerja warga membuat persembahan (arti kata bali) berupa sesajen/sesajen maka menyebabkan adanya hujan sebagai sumber penghidupan di bumi ini. Pura merupakan linggih/ sthana para dewa-dewi yang merupakan sumber kekuatan memberikan perlindungan dari adanya marabahaya seperti tanah longsor, banjir, angin ribut maupun memberikan aura magis angker sehingga masyarakat tidak berani mengganggu tumbuhan sekitarnya. Ketiga pura yang terletak di perbatasan bagian barat kebun raya, bagaikan sebuah tanggul penyangga (buffer) niskala untuk melindungi hutan Bukit Tapak diatasnya yang rawan longsoran. Terjaganya kelestarian hutan Bukit Tapak berarti mencegah adanya longsoran, banjir dan menjaga fungsi hydrologi hutan sebagai tangkapan air untuk Danau Beratan tersebut. Secara umum masyarakat pada kawasan memiliki budaya tradisional dalam menyikapi keberadaan alam, dan untuk mewujudkan kehidupan yang nyaman, selaras, dan seimbang diantaranya dengan bersyukur kehadapan Tuhan Yang Maha Esa atas segala karunia dan ciptaan-Nya di alam ini sehingga bisa mengisi kehidupan dengan baik sesuai dengan Pilosofi THK. Berdasarkan penelitian yang dilakukan Penerapan THK pada seluruh desa di kawasan Bedugul memiliki acuan yang sama dan sudah di bagi dalam segala hal seperti :

1. Pelestarian terhadap sejarah kawasan: masyarakat harus mengingat sejarah asal usul dan tempat berstananya Dewa-Dewa yang ada di sekitar Kebun Raya Bali, serat menjaga kearifan local seperti, upacara keagaman di masing-masing Pura yang ada di area Kebun Raya Bali.

2. Pelestarian lingkungan: masyarakat sekitar Kebun Raya Bali wajib menjaga lingkungan dengan seluruh tanaman yang ada di area kebun raya dengan menjaga tanaman warisan dari leluhur.

3. Pelestarian budaya: masyarakat harus ingat upacara (wali-walian) di pura yang berada disetiap di area kebun raya bali seperti Pura Teratai Bang, Pura Batu Meringgit, dan Pura Giri Putri yang diempon oleh Umat Hindu Kebun Raya Bali.

4. Perlindungan sumberdaya alam di Kebun Raya Bali yaitu dilakukannya konservasi tumbuhan serta upacara pada tumbuhan pada acara tumpek yang dilakasanakan setiap 6 (enam) bulan sekali.

\section{Hubungan Manusia Dengan Alam}

Tri Hita Karana dalam filosofi budaya Bali juga telah menjadi prioritas Kebun Raya Bali dalam pengembangan koleksi etnobotani. Etnobotani adalah 


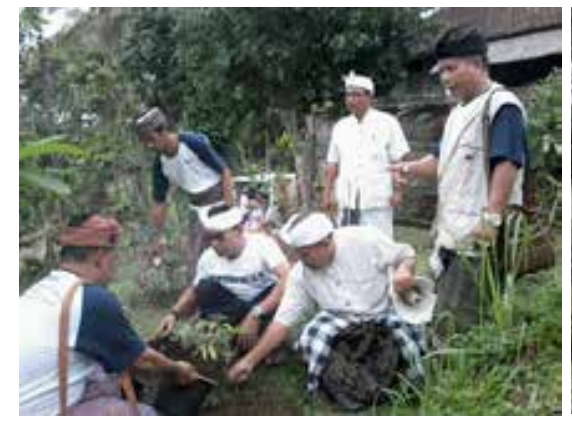

Foto 3. Peran Kebun Raya Bali dalam konservasi tumbuhan bekerjasama dengan Kab. Tabanan (kiri). Kanan: pihak Swasta.

pengetahuan masyarakat etnis dalam memanfaatkan tumbuhan, mineral, atau material lainnya secara tradisionil. Dalam hal ini upaya konservasi tumbuhan etnobotani yang bangun oleh Kebun Raya Bali yaitu Taman Usada dan Taman Panca Yadnya yang didalamnya banyak memuat nilainilai budaya Bali. Dalam penerapan konsep Tri Hita Karana tersebut terpadu dengan kajian ilmiah. Kegiatan ilmiah dilaksanakan dalam pengembangan koleksi etnobotani melalui kegiatan eksplorasi dan penelitian pada wilayah masyarakat tradisional Bali yang disebut masyarakat Bali Age. Komunitas masyarakat Bali Age memiliki budaya yang masih kuat mempertahankan tradisinya secara turun temurun, dan menyadari alam lingkungan yang menjadi sumber kehidupannya harus tetap dipertahankan.

Dari Foto3. Dapat dilihat peran penting Kebun Raya Bali dalam menunjang konservasi untuk mempertahankan pentingnya memanfaatkan tumbuhann dan mengelola lingkungan untuk bisa bertahan atau menekan terjadinya perobahan alam yang tidak menguntungkan. Keberadaan Kebun Raya Bali dan kearipan local yang ada pada masyarakat cenderung dapat dipakai sebagai salah satu acuan dalam konservasi.

\section{Hubungan Manusia dengan Sesama}

Hubungan manusia dengan manusia (pawongan) terdapat hubungan yang sangat kompleks. Keduanya saling berinteraksi, saling membutuhkan, saling melengkapi dan saling bergantung satu sama lain. Dalam hubungannya dengan lingkungan, manusia merupakan suatu oganisme hidup (living organism). Terbentuknya pribadi seseorang dipengaruhi oleh lingkungan bahkan secara ekstrim dapat dikatakan, setiap orang berasal dari satu lingkungan, baik lingkungan vertikal (genetika, tradisi), horizontal (geografik, fisik, sosial), maupun kesejarahan.

Pawongan terjalin dalam suatu sistem yang dikenal dengan desa adat, menurut Peraturan Daerah Provinsi No 3 Tahun 2001 bahwa desa adat yang merupakan suatu kesatuan masyarakat hukum adat yang dijiwai oleh 


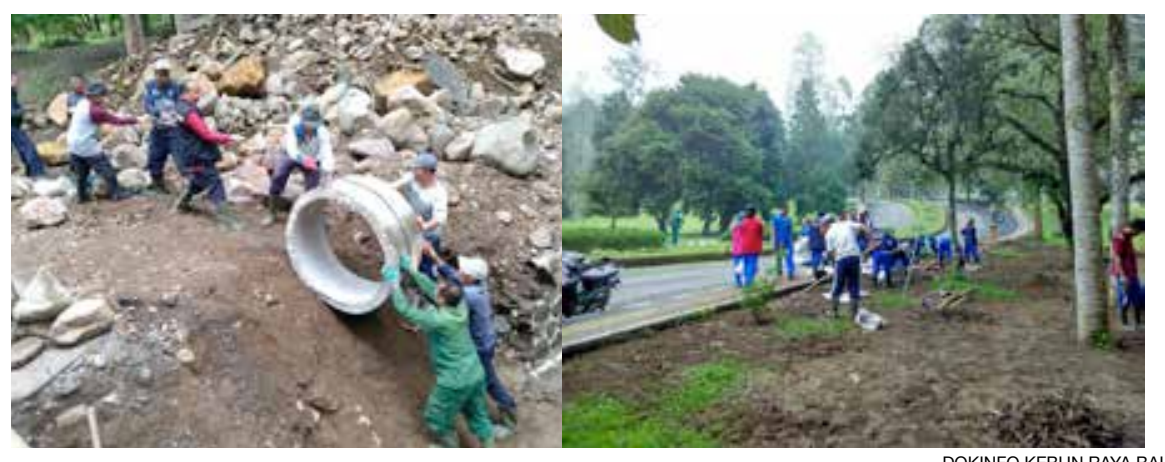

DOKINFO KEBUN RAYA BALI

Foto 4. Kerjasama dalam pembangunan jembatan di Kebun Raya Bali (kiri). Gotong Royong dalam penataan taman (kanan).

ajaran agama hindu dan nilai-nilai budaya yang hidup di Bali sangat besar peranannya dalam bidang agama dan sosial budaya sehingga perlu diayomi, dilestarikan dan diberdayakan. Sebagai masyarakat desa adat terdapat aturan yang mengikat untuk saling menghormati dengan yang lain serta memandang antar sesama adalah sama (tat wam asi).

Kebun Raya Bali merupakan kawasan konservasi yang dimiliki bersama. Masyarakat disekitar Kebun Raya Bali memiliki peran dan tanggung jawab dalam menjaga keharmonisan, konservasi dan budaya dalam penerpan Tri Hita Karana di Kebun Raya Bali seperti misalnya masyarakat lokal yang terdiri dari empat desa saling menjaga hubungan sehingga terbentuk kerjasasma. Dari hasil wawancara dan pengamatan langsung dapat dilihat kerja sama masyarakat dan karyawan Kebun Raya Bali dalam membangun Kebun Raya Bali, pada pasca banjir dengan cara gotong royong.

Melihat Foto4, peran masyarakat sangat penting hubungan yang harmonis dalam menjaga konservasi dan budaya. Masyarakat yang berada di wilayah Kebun Raya Bali sangat berperan penting dalam Penerapan Tri Hita Karana pengelolaan Kebun Raya Bali untuk menjaga konservasi dalam keharmonisan.

\section{Nilai Harmonisasi, Konservasi dan Budaya dalam Penerapan Tri Hita Karana di Kebun Raya Bali}

Berdasarkan analisis, dan hasil wawancara terhadap pengelola Kebun Raya Bali, tokoh adat, karyawan yang sudah purnabati, orang suci (pemangku) di masing-masing Pura serta observasi lapangan, nilai konservasi dari penerapan THK dapat disajikan pada table 3 .

Nilai keharmonisan, konservasi dan budaya yang terkandung dari penerapan nilai THK oleh masyarakat disekitar Kebun Raya Bali berdasarkan tiga pilar utama yang sangat berperan penting dalam menciptakan keharmonisan dalam kehidupan, adalah hubungan manusi dengan sang 
Tabel 3. Bentuk dan aktivitas masyarakat dalam penerapan Tri Hita Karana dalam Harmonisasi konservasi dan budaya di Kebun Raya Bali

\begin{tabular}{|c|c|c|c|}
\hline $\begin{array}{c}\text { Prinsip Harmonisasi, } \\
\text { Konservasi, dan } \\
\text { Budaya }\end{array}$ & $\begin{array}{l}\text { Aktivitas } \\
\text { masyarakat }\end{array}$ & Nilai THK & Jenis Kegiatan \\
\hline $\begin{array}{l}\text { Konservasi dalam } \\
\text { menjaga lingkungan }\end{array}$ & $\begin{array}{l}\text { Melakukan } \\
\text { penanaman dan } \\
\text { penghijauan }\end{array}$ & $\begin{array}{l}\text { Sebagai salah satu } \\
\text { hubungan manusia } \\
\text { dengan alam }\end{array}$ & $\begin{array}{l}\text { Bekerjasama dengan } \\
\text { Kebun Raya Bali } \\
\text { dalam penyediaan } \\
\text { tanaman }\end{array}$ \\
\hline $\begin{array}{l}\text { Kepedulian } \\
\text { masyarakat terhadap } \\
\text { pura-pura yang ada di } \\
\text { kawasan Kebun Raya } \\
\text { Bali }\end{array}$ & $\begin{array}{l}\text { Masing-masing desa } \\
\text { di berikaan tanggung } \\
\text { jawab terhadap pura } \\
\text { yang ada }\end{array}$ & $\begin{array}{l}\text { Sebagai salah satu } \\
\text { hubungan manusia } \\
\text { dengan sang pencipta }\end{array}$ & $\begin{array}{l}\text { Melaksanakan acara } \\
\text { piodalan (upacara } \\
\text { dewa yadnya) setiap } \\
\text { enam bulan dan } \\
\text { mecaru }\end{array}$ \\
\hline $\begin{array}{l}\text { Peran masyarakat } \\
\text { local dalam penataan } \\
\text { Kebun Raya Bali }\end{array}$ & $\begin{array}{l}\text { Bekerja sama dengan } \\
\text { masyarakat local } \\
\text { dengan pegawai } \\
\text { Kebun Raya dalam } \\
\text { penataan Kebun Raya } \\
\text { Bali }\end{array}$ & $\begin{array}{l}\text { Sebagai hubungan } \\
\text { manusia dengan } \\
\text { sesama }\end{array}$ & $\begin{array}{l}\text { Gotong royang pada } \\
\text { pasca bencana alam di } \\
\text { Kebun Raya Bali }\end{array}$ \\
\hline
\end{tabular}

pencipta, hubungan manusia dengan lingkungan/alam dan hubungan manusia dengan sesama.

Berdasarkan Table 3. Dapat dilihat hasil dari penerapan Tri Hita Karana dalam keharmonisan konservasi, dan budaya di Kebun Raya Bali, sudah di laksanakan sesuai dengan peran Tri Hita Karana dalam kehidupan. Melalui penerapan nilai-nilai filosofi yang masyarakat sekitar kawasan Kebun Raya Bali meyakini sebagai dasar dalam pengembangan wisata Kebun Raya Bali mampu meningkatkan rasa memiliki terhadap kawasan Kebun Raya Bali. Menurut Alianda (2008) wisata berbasis lingkungan (ekowisata) dilaksanakan dengan kesederhanaan, memelihara keaslian alam dan lingkungan, adat istiadat, seni dan budaya, kebiasaan hidup, kesunyian, memelihara flora dan fauna, serta terpeliharanya lingkungan hidup sehingga tercipta keseimbangan antara manusia dengan lingkungan alam sekitar. Penerapan nilai budaya dan agama oleh masyarakat yang berada disekitar Kebun Raya Bali nantinya dapat menjadi dasar pengembangan kawasan wisata berbasis alam.

\section{Kesimpulan}

Penerapan nilai-nilai filosofi THK masyarakat sekitar kawasan Kebun Raya Bali meyakini sebagai dasar dalam pengembangan wisata alam Kebun Raya Bali Penerapan konsepsi THK di Kebun Raya Bali memiliki peranan penting karena tiga pilar utama tersebut tidak hanya untuk menjamin kepentingan publik maupun individu tetapi juga untuk meningkatkan efisiensi sumber daya, menjaga hubungan dengan sang pencipta, konservasi lingkungan dan budaya, serta menjaga keharmonisan dalam mengurangi 
konflik, mengurangi ketimpangan sosial, dan menjamin keberlanjutan pembangunan wilayah. Konsep ini juga dapat diterapkan di daerah lain maupun negara lain sebagai dasar pengembangan wisata sesuai dengan budaya setempat dan ajaran agama masing-masing. Hal ini dikarenakan setiap ajaran agama umumnya mengajarkan kita untuk senantiasa menjaga alam, melestarikan alam dan bersahabatan dengan alam untuk menjadikan hubungan yang harmonis.

Konsep budaya masyarakat Bali menjadi salah satu pedoman dalam pembangunan dan pengembangan Kebun Raya Bali terkait dengan konservasi tumbuhan. Secara umum nilai-nilai filosofi yang ada pada masyarakat di Bali hanya sebagian kecil bisa dikemas dalam taman tematik seperti Taman Panca Yadnya dan Taman Usada. Dalam hal ini sesuai dengan keberadaan letak topografi kebun Raya Bali pada kawasan pegunungan, sehingga tumbuhan yang dikonservasi hanya jenis-jenis tumbuhan pegunungan dan jenis-jenis tumbuhan lainnya yang bisa toleransi tumbuh di pegunungan.

Informasi tumbuhan terkait dengan etnobotani budaya Bali masih relatif banyak belum terinventaris di Kebun Raya Bali. Informasi tersebut sangat penting sebagai pendukung jasa pendidikan bagi masyarakat luas utamanya konsep tentang pemahaman dalam memanfaatkan dan mempertahankan alam lingkungan, serta berbagai kegiatan ritual yang ada dalam hidupan budaya masyarakat Bali untuk mencapai keseimbangan, yang telah dikenal dengan konsep THK. Terkait dengan THK tersebut ke depannya Kebun Raya Bali dalam kegiatan konservasi tumbuhan perlu berupaya untuk lebih mengoptimalkan lagi di bidang etnobotani budaya Bali.

\section{Ucapan Terima Kasih}

Penulis mengucapkan terima kasih yang sebesar-besarnya kepada Wawan Sujarwo, PhD, selaku pembimbing, Renata Lusilaora selaku pendamping dan memberikan supports dalam pembuatan artikel ini

\section{Daftar Pustaka}

Alianda FMZ. 2008. Perencanaan dan Desain Lanskap Tapak Ekowisata: Ekotourisme Teori dan Praktek. Aceh (ID): CV Tamita Perdana

Agung A A G. 2010. Identitas Bali: antara Falsafah dan Pariwisata. Jurnal ilmiah hospitaliti. Vol 1(1): 1-15.

Hadi SP. 200o. Manusia dan Lingkungan. Semarang (ID): Universitas Diponogoro. Peters J H and Wisnu W. 2013. Tri Hita Karana the Spirit of Bali. Jakarta: Gramedia. Putra A M. 2012. Strategi pengelolaan puri agung sebagai daya tarik wisata di Desa Kerambitan, Kecamatan Kerambitan, Kabupaten Tabanan. Jurnal perhotelan dan wisata. 2(1):1-24.

Setiadi, Wawan and Renata Lusilaora. 2017."Ethnobotanical Tourism Potential in Bali Botanical Garden". JUMPA 3 [2]: 387-396. 
Sudarsana,IK. 2002. Purana Pura Watu Ringgit, Panitia Pemugaran Kayangan Jagat Pura Batu meringgitPemuteran. Baturiti, Bali.

Suyarto, R. 2002. Kajian Longsor Lahan : Studi kasus di Kawasan Bedugul-Bali. Jurnal Lingkungan Hidup : Bumi Lestari Vol 2 No 1 Februari 2002. ISSN 14119668.

Sugiyono. 2008. Metode Penelitian Pendidikan. Bandung : Alfabeta.

Tirta,IG. 2004, Konservasi Tanaman yang digunakan dalam Upacara Agama si Kabupaten Bangli-Bali. Prosiding Seminar Konservasi Tumbuhan Upacara Agama Hindu 2004. Kebun Raya "Eka Karya” Bali-LIPI.

Yayasan Wisnu. 2011. Desa Berdaulat Menuju Keterbukaan Dunia, Panduan Mengelola Bersama Potensi Wisata Ekologis. Denpasar: Wisnu Press.

\section{Profil Penilis}

I Gusti Ngurah Putu Dedy Wirawan, lahir di Sempidi 24 Juli 1987. Tahun 2008 menyelesaikan program D3 Pariwisata di Sekolah Tinggi Pariwisata Bali, dan pada tahun 2013 menyelesaikan D4 Pariwisata di Universitas Udayana. Pernah bekerja di hotel dan restauran swasta, tahun 2009 sampai sekarang bekerja di Balai Konservasi Tumbuhan Kebun Raya "Eka Karya” Bali LIPI, pada unit pelayanan jasa dan informasi, sebagai Humas. Email: dedywirawan76@yahoo.co.id

I Made Raharja Pendit lahir di Tabanan 15 April 1961. Tahun 2002 menyelesaikan program S1 Pertanian di Universitas Panji Sakti Singaraja. Saat ini bekerja di Balai Konservasi Tumbuhan Kebun Raya "Eka Karya" Bali - LIPI pada Unit Jasa dan Informasi. Penulis berminat untuk mempublikasikan potensi wisata dan etnobotani terkait dengan fungsi lembaga tempat penulis bekerja dalam bidang konservasi tumbuhan.Email:madependit@gmail.com 